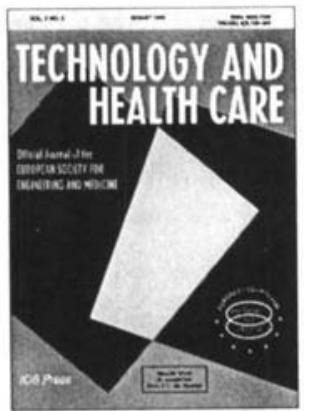

\title{
Technology and Health Care
}

\section{Official Journal of the European Society for Engineering and Medicine}

Covering the overlapping areas between physics, engineering, informatics and human biology, basic medical sciences, clinical medicine; and presenting a forum for the discussion of socio-economic aspects related to medical technology

\begin{abstract}
Aims and Scope
Technology and Health Care is intended to serve as a forum for the presentation of new concepts, procedures, and devices associated with the utilization of technology in medicine as well as their socio-economic impact. As such, it covers all areas of Biomedical Engineering, in particular: Diagnostic and Therapeutic Procedures and Devices; Bioelectronics and Biomagnetism; Biocompatibility, Artificial Organs and Implants; Clinical Laboratory and Laboratory Automation; BME in Biotechnology, Cellular and Molecular Technology; Medical Informatics, Systems Analysis, Neuroinformatics; Rehabilitation; General Society-Related and Health PolicyRelated Topics; Problems Relating to Animal Experiments; BME in Basic Physiological and Medical Sciences; Biosensors, Medical Micro- and Nanotechnology; Medical Physics; Drug Delivery Systems; BME in Genetic Engineering; Patient Monitoring; Efficacy of Diagnostic and Therapeutic Procedures; Biomedical Ethics; Education in BME.
\end{abstract}

\section{Editor-in-Chief}

P. F. Niederer

Institute of Biomedical Engineering

and Medical Informatics

Swiss Federal Institute of Technology and

University of Zürich

Moussonstraße 18, CH-8044 Zürich, Switzerland

Tel.: +4l 16324568 , Fax: +4l 16321193

E-mail: niederer@biomed.ee.ec.ethz

\section{Associate Editors}

A. Dittmar, R.J. Green, J.L. Healy, C.N. Schizas, W. Sansen, S.M. Lavelle.

\section{Editorial Board}

T. Bajd, J.E.W. Beneken, G.R. Bock, J.A.S. Carruth, J. Demongeot, G. Ferrigno, C. Frigo, D. Jones, D Koutsouris, D. Liepsch, P.F. Salvans, F.H.J. Lopes da Silva, P.P. Lunkenheimer, J.-P. Morucci, D. Navajas, L. Nolte, A. Penotti, M.J. Peters, F. Podo, B.S. Proimos, P Ruiegsegger, K. Schaarschmidt, C.J.P.M. Teirlinck, J.M. Thijssen, F. Walloch

\section{Call for Papers}

Technology and Health Care contains original scientific contributions, review type articles (upon invitation), tutorials, editorials, short communications, discussion papers on controversies, news and announcements of interest to the bioengineering community and other papers which reflect the Aims and Scope of the Journal. Contributions should be submitted to the Editor-in-Chief and are subject to a peer review procedure.

\section{Subscription Information}

Technology and Health Care (ISSN 0928-7329) is published in one volume of 6 issues a year. The subscription price for 1998 (Volume 6) is NLG 570/US\$ 311 (including NLG 60/US\$36 for postage, packaging and handling).

\section{Abstracted / Indexed in}

CABS database, EMBASE, Index Medicus, INSPEC, Medline.

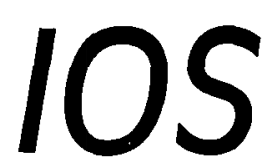

$\operatorname{Press}$

IOS Press is a STMP publishing house, publishing for an international audience both books and journals in a wide range of fields, such as Medical Science and Technology, Artificia Intelligence, Computer Science, Telecommunication, Information and Administrative Science, Physics, Biology and Design and Manufacturing.

For a free sample or more information, please contact the Promotion Department of: IOS Press, Van Diemenstraat 94, $1013 \mathrm{CN}$ Amsterdam, The Netherlands Fax:+31206203419 Email:market@iospress.nl URL: http://www.iospress.nl 


\section{Cambridge-The Healthcare Ethics Authority}

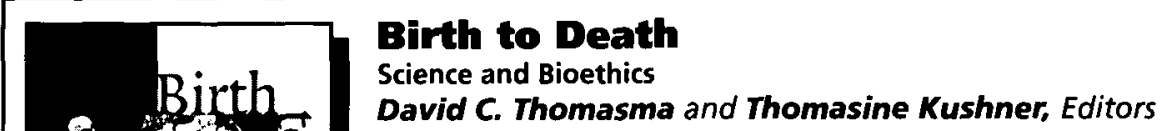

This text, whose editors bring you Cambridge Quarterly of Healthcare Ethics, reviews the major biological advances of recent years and explores their ethical implicarions. The fascinating contributions guide the reader through many critical issues that face our technologically advanced society.

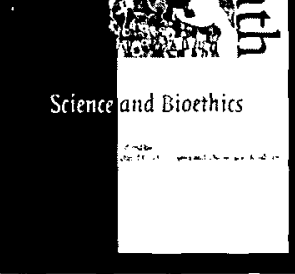

\section{Medical Futility}

And the Evaluation of Life-Sustaining Interventions

Marjorie B. Zucker and Howard D. Zucker, Editors

This book surveys the clinical, ethical, religious, legal, economic and personal dimensions of decision making in situations when the choice is between extending costly medical treatment of uncertain effectiveness, or terminating treatment thereby ending the patient's life. Contributors from various disciplines offer perspectives on issues ranging from the definition of medical futility to the implications for care in various clinical setrings. 1997 C.192 pp. 56020-9 Hardback \$64.95* 56877-3 Paperback $\$ 24.95$

\section{The Troubled Helix}

Social and Psychological Implications of the New Human Genetics

Theresa Marteau and Martin Richards, Editors

"... a serious attempt to present both the general reader and specialists in clinical genetics with some insights into the practical problems of the social and psychological aspects of modern human genetics....

[I]t contains a lot of new and valuable information about patients' and geneticists' perceptions of genetic disease, together with some insights into the successes and difficulties of research directed at improving how we communicate. Hence it is a very timely addition to the publications on buman genetics, and medical genetics in particular."

-D.J. Weatherall,

British Medical Journal

1996377 pp. 46288-6 Hardback \$64.95

\section{Improving Nature?}

The Science and Ethics of Genetic Engineering Michael J. Reiss and Roger Straughan

"The book includes ethical concerns for the whole spectrum of life... and is rich with extended examples... The authors recognize that ethics can't provide conclusive answers about the rightness and wrongness of genetic engineering, but they clearly present the risks and benefits that inhere in creating genetically altered organismes... The choices are still in our hands; this book can help us make them more intelligently."

-Science

1996298 pp. $45441-7$ Hardback $\$ 24.95$

\section{Now in paperback...}

\section{Euthanasia Examined}

Ethical, Clinical and Legal Perspectives John Keown, Editor

Regrettably, the euthanasia debate is too often characterized by rhetoric rather than reason. This book aims to inform the debate by acquainting anyone interested in this vital question with some of the major ethical, legal, clinical and theological issues involved. The essays it contains are authoritative in that they have been commissioned from some of the world's leading experts, balanced in that they reflect divergent viewpoints (including a vigorous debate between two eminent philosophers), and readable in that they should be readily understood by the general reader.

"Of all the ethical issues in medicine, euthanasia... is the most important... Euthanasia Examined: Ethical, Clinical, and Legal Perspectives is by far the best guide... I have ever come across."

-Raymond Tallis,

Times Literary Supplement 1997356 pp. 58613-5 Paperback \$24.95* 


\section{International Journal of Technology Assessment in Health Care}

\section{Instructions for Contributors}

The editors welcome submissions of articles that deal with the wide range of topics related to technology assessment in health care-policy, practice, diffusion, economics, ethics, law, and social and cultural perspectives. Authors should send one original and 2 clean copies of their manuscript. The final version will be required on computer diskette upon acceptance of the paper. Articles must be in English. Spelling, capitalization, and punctuation should conform with the 13th Edition of The Chicago Manual of Style (University of Chicago Press). Articles and correspondence should be sent to: Stanley J. Reiser, MD, PhD, The University of Texas-Houston Health Science Center, P.O. Box 20708, Houston, Texas 77225, USA; or Egon Jonsson, PhD, The Karolinska Institute and the Swedish Council on Technology Assessment in Health Care, P.O. Box 5650, S-114 86, Stockholm, Sweden.

Preparation of ManUSCRIPT. The entire manuscript, including all notes and references, must be typed, doublespaced on $8 \times 11$ inch or A4 paper, with at least 1 inch margins. Manuscript pages should be numbered consecutively. Manuscripts should be arranged as follows: 1) cover sheet; 2) abstract and key words; 3) acknowledgments, including source of funding; 4) text; 5) notes; 6) references; 7) appendix; 8) tables with titles; and 9) figures, with captions on a separate page. Manuscripts should typically include no more than 20 pages of text ( 6000 words). Acronyms should be clearly spelled out on first use. The use of product trade names should be avoided; generic names should be used except where discussion of proprietary brands is essential to the manuscript.

COVER SHEET AND Cover LETTER. A cover letter, signed by all authors, must attest that 1) each named author contributed to both the conception/design and/or analysis/interpretation of the project and the writing of the paper; 2) each has approved the version being submitted; and 3) the content has not been published nor is being considered for publication elsewhere.

As relevant to the content of the paper, the letter should also attest to the fact that any research with human or animal subjects conforms to the legal standards of the country in which it was performed. All authors must disclose any financial arrangements with companies whose products are discussed in the paper or their competitors; such information will not be revealed to reviewers, but may be included in a suitable format in the final publication if the manuscript is accepted. The cover letter should also provide all authors' full names, professional degrees, and institutional mailing addresses.

The cover sheet should list the article's title, the name, complete mailing address, telephone and fax numbers, and e-mail address of the corresponding author, and a short title (50 characters or less) for the running head.

ARSTRACT AND KEY WORDS. A 250-word abstract should summarize the objectives of the study or analysis, the article's major arguments and/or results, and its conclusions/recommendations. Abstracts must be submitted in 4 sections: Objectives; Methods; Results; and Conclusions, except where the subject and/or format of the article do not permit. Three to 5 key words, using terms from the Medical Subject Headings from Index Medicus, should follow the abstract.

REFERENCES AND NOTES. Bibliographic citations in the text are indicated by in-line numbers in parentheses; these numbers correspond to the relevant works' order in the alphabetized reference list (see below).

In-fext citations: ". . . Jones and Smith (7) maintained that. . .."

If more than one reference is cited at a specific place in the text, semicolons should separate each reference number; if page numbers are included, commas should separate each reference number from its page number(s).

Multiple citarions without page numbers: .. . This system has been dealt with at length in the literature $(1 ; 2 ; 12-14)$.

Multiple citations with page numbers: . . This system has been dealt with at length $(1,1-10 ; 3,5 ; 12,25-57 ; 14,102-46)$.

REFERENCE LIST. The reference list must be in alphabetical order and each entry must be numbered accordingly. If a work has more than five authors, the first three authors should be listed, followed by et al. Titles of journals must not be abbreviated.

Book: 9. Jones, A.B., \& Smith, J.K. Computer diagnosis and results. New York: Penta Publishers, 1978.

Journal; 9. Jones, A.B., \& Smith, J.K. The relationship between health needs, the hospital, and the patient. Journal of Chronic Disease, 1985, 32, 310-12.

Article in edited work: 9. Jones, A.B., \& Smith, J.K. The diagnostic process. In R. Brown \& T. Wilson (eds.), New technology and its medical consequences, vol. 1. New York: Apple Publishers, 1972, 101-34.

When more than a simple source citation is called for, endnotes may be used. Notes should be numbered consecutively throughout the text and typed together on a separate page preceding the reference section. Source citations within notes follow the same style of citations in text.

TABLES AND Figures. Tables and figures should be numbered consecutively and appear as one unit after the reference section. All tables and figures must have a caption, and must be cited in the text. Abbreviations in tables and figures should be avoided, except in the case of acronyms already used in the text. Table footnotes appear directly after the table body; table references follow the footnotes. Figures must be black and white and camera ready, either as glossy prints or original laser printed paper versions. All figures should remain legible at a $50 \%$ reduction in size.

PERmissions. Authors are responsible for obtaining written permission to publish material for which they do not own the copyright, including material from the Internet. Contributors will be asked to assign their copyrights, on certain conditions, to Cambridge University Press.

Copyediting and Proofreading. The publishers reserve the right to copyedit and proofread all accepted articles, but the lead author will be asked to review the copyediting if changes have been substantial. Page proofs will be sent to the lead author for correction of typographical errors.

OFFPRINTS. The lead author will receive 25 offprints free of charge; additional numbers may be purchased if ordered at proof stage. 


\section{INTERNATIONAL JOURNAL OF TECHNOLOGY ASSESSMENT IN HEALTH CARE}

\section{Featured Special Sections and Guest Editors in Forthcoming Issues}

An Early Warning System for Health Technology Assessment

Per Carlson, SBU, Sweden

Torben Jørgensen, Danish Hospital Institute, Denmark

Assessing Reproductive Technology

Elina Hemminki, STAKES, Finland

Miriam Orleans, University of Colorado, U.S.A.

Bayesian Approaches to Technology Assessment and Decision Making

Bryan R. Luce, MEDTAP International, U.S.A.

Assessing Clinical Guidelines

Jaime Caro, Caro Associates, U.S.A.

Alternative and Complementary Medicine

Bernard Bloom, University of Pennsylvania, U.S.A.

Tore Scherstén, SBU, Sweden 